\title{
ANALYSIS OF GEOMAGNETICALLY INDUCED CURRENT IN POWER GRID DURING GEOMAGNETIC STORM
}

\author{
Smit Anjana \\ Department of Electrical Engineering \\ CHARUSAT, Anand, Gujarat, India
}

\begin{abstract}
Solar storms are event that has a big range of averse outcome on technological system, power grid specifically. During extreme geomagnetic storms a GIC begin to travel between long transmission lines or conducting constructions. The possibility of solar storms features an approximately linear relation with the sun spot activity level that fluctuates in eleven years cycle. This paper could be threat examination of GIC in power system and describe the causes, the implications, each on power system apparatus level and on power system level. When GIC flow in neutral of transformer winding it start to causes the Half-cycle core saturation and produce high level of harmonics can sense bad fault situation to protective relays and mis-operation of circuit breakers. Also this paper mentioned potential risk mitigation ways.
\end{abstract}

Keywords - power grid, Geomagnetic Disturbance, Geomagnetically induced Current (GIC), GIC mitigation methods, half-cycle saturation, Harmonic generation, Harmonics, Solar Storm

\section{INTRODUCTION}

The sun ejects coronal mass ejection, it travels through space and collides with earth's magnetism. This disturbance penetrate the Earth's magnetosphere and it may outcome in great current electrojet in ionosphere. Current varies with time so it produce field on ground. Because of this field current will flow in ground. And in high ground resistive area this current flow in transmission lines through neutral of power transformer. So due to geomagnetic storm the current flow in transmission line is known as geomagnetically induced current (GIC)[1-3]. This induced current has very low frequency about 0.1 to $0.001 \mathrm{~Hz}$ (Quasi-DC) $[4,5]$. The normal current of GIC during storm is 10-15A. GIC passing through such human made conducting structure have the potential to cause great harm to it[6]. Overall GIC is particularly prevalent in high-attitude areas with high recurrence rates [7]. For power grid especially, geometrical and alignment settings even have an important influence, converters placed in the corner of the grid and when only long power lines are at high risk of GIC. GIC and Geomagnetic storms are not just the complexity of the energy system; and may directly

\author{
Mihir Patel \\ Department of Electrical engineering \\ CHARUSAT, Anand, Gujarat, India
}

affect technology applications such as, HF-radio, GPS, rail, communication system, plumbing and land surveying [8]. In gas pipelines, GIC can cause diversions in the pipeline to electrical power which can disrupt the cathodic protection system [9].

The first case of GIC was detected in a telegraph system [10], in early 1848 there were a few studies on the social impact of climate change. Not only did the Hydro-Québec power outage emerge during the March 1989 geomagnetic storm, which left many people without electricity for up to nine hours, when solar storms widely were considered a threat to society and to their critical infrastructure [11]. Halloween storm of 2003 when parts of Malmö were left without electricity for 2050 minutes. $300 \mathrm{~A}$ Is the largest GIC-current ever measured in the world and it was seen in Sweden 2004 [1]. While the strength of the GIC and Geoelectric forums in high-altitude environments, the interaction between GIC at the Swedish and Greek gas channels has clearly shown that this will not be a neighbourly thing [12].

\section{ANALYSIS OF HISTORICAL SOLAR STORM EVENTS}

\section{A. The Carrington Event, $1^{\text {ST }}$ September 1895}

On the sunrise of $1^{\text {st }}$ September 1895 Richard Carrington detect a formerly unknown event, an extreme solar flare. The geomagnetic storm collide with earth's magnetic field after 17 hours it also took days. All over the world this storm was noticed. Auroras where it was found as close to the equator as the Caribbean. For some information it was clear enough to read the article in the light of aurora only [13]. Telegraph structure went down everywhere in Europe and Northern America, in some areas they even provide electrical shock to workers and cause fires [14]. There are recent storms of comparable magnitude relative to certain boundaries, but in all Carrington event is considered to be the strongest storm of the last five hundred years [15].

In 1895 the use of electrical appliances was its start and the results of the Carrington event were greatly reduced if such an event where it takes place today it is very difficult to assess the damage to the community due to the limited continuity of important public infrastructure. A study by the US 


\section{International Journal of Engineering Applied Sciences and Technology, 2020 Vol. 5, Issue 8, ISSN No. 2455-2143, Pages 235-241 \\ Published Online December 2020 in IJEAST (http://www.ijeast.com)}

National Academy of Sciences revealed a cost of between US $\$ 1$ trillion to US \$ 2 trillion in the first year alone and recovery periods of four to ten years.[14].

\section{B. The Hydro-Québec Event, $13^{\text {TH }}$ March 1989}

GIC effect was noticed in Canadian power system due to which great awareness was created in utilities throughout the world. On 13-14 March, 1998 geomagnetic storm with 500nT/min magnitude was experienced by the earth[16]. Due to this storm complete Québec grid was collapsed in twentyfive seconds. Seven "static var compensators" was online trip. So that 0.2 p.u. voltage drop noticed. Due to loss of synchronism, Montréal's five lines was tripped and whole power network separated. Total 21,500 MV of power lost due to this storm. Duration of blackout was nine hours and in this nine hours 6 million people of Québec was affected by the storm[17].

About 200 different storm-related incidents were also reported from North America, where the catastrophic failure of the transformer at the Atomic Power Plant in New Jersey may have been the most severe one $[14,18]$.

Shortly after the blackout of Hydro-Québec prepared a team of engineers to investigate the incidents and propose remedial measures [19]. According to the following actions have since been applied:

- Rise the trip level and recalibrate the protection systems. This approach has verified effective, after 1989 there were too many strong magnetic storms but they did not cause any problems.

- Creation of actual time warning arrangement measuring grid interference during solar storms.

- Adjustment of energy system processes. In the event of a disruption, Hydro-Québec reduces power flow to DC transmission lines and connections, and suspends all major switching operations.

- By installing series compensation on power lines it increases system stability. This is very effective in reducing the effect of magnetic fields.

At the Salem Atomic Power Plant damaged step-up transformer needed to be changed. If current auxiliary components of transformer are not found then the time interval for manufacture of spare components would be close to two years, when order has greatest importance. The total budget for maintenances and replacement electricity for the vendor was future projected to be more than US\$ 20 million[14].

\section{C. "The Halloween Storm”, 30 $30^{\text {TH }}$ October 2003}

Double Coronal Mass Ejections (CMEs) hit ground next to each other at a time. First coronal mass ejected from Sun at 11:10 (UTC) on the 28th Oct. 2003 and hit the ground about 19 hours later at about 06:10 (UTC). The second Coronal mass ejected at 20:49 (UTC) and touched ground at 16:20 (UTC). At 20: 4 (UTC) the storm is high and as a result the geoelectric field reached a value of $2 \mathrm{~V} / \mathrm{km}$ within the Malmö area [1].
On $30^{\text {th }}$ Oct. at 22:07 (UTC) a grid collapsed for 20-50 minutes and impacted on 50,000 clienteles in Malmö and nearby zones. The main source of the blackout was $130 \mathrm{kV}$ system's relay. The relay is programmed very much responsive to the $3^{\text {rd }}$ harmonic $(150 \mathrm{~Hz})$ of the primary frequency $(50 \mathrm{~Hz})$ who is the effected from transformer saturation because of GIC produced by geoelectric field which is about $2 \mathrm{~V} / \mathrm{km}[1,20]$.

Also Swedish power plant experienced $13^{\circ} \mathrm{C}$ increase in transformer oil in top oil temperature who holding 69 tons of oil ahead of mitigation steps were taken to permit the transformer for drop down temperature.

Similar storm is observed to made major damage in South Africa's transformer. During this period 15 transformers are damaged in the country [21-23].

In Swedish Atomic Power Plant Two transformer have been changed. One transformer has a new design that makes it stronger against GIC. In the Second transformer resistor was placed between ground and neutral, to offer it a better sufferance to GIC but it may move forward elsewhere within the power grid.

\section{EFFECT OF GIC ON POWER SYSTEM}

\section{A. Power Disruption}

The power supplied in the grid at dissimilar voltage ranges. For long transmission lines high voltage level are used. Mostly high voltage levels (130kV and above) are arranged in mesh formation and small voltage ranges $(50 \mathrm{kV}$ and below) are arranged in radial formation. In the mesh arrangement if relay trips one line at that time only load sift to other transmission lines so it increase stress level on the transmission lines but it would not cause a power outage. But in radial configuration if the protective relay trip then downward from the relay will out of electricity till the relay had been restore. Exactly this thing happen in Malmö on 30 ${ }^{\text {th }}$ Oct. 2003 when 50,000 customers are detached from power [20].

Due to loss of the power consumption it could be affect remaining power system. Sever solar storms increase tension in the power system because of increase transformer losses, drastically increase in reactive power consumption and probable loss of power [24].

Local power failure may have wrecked transformers and just like that circumstance it can take a considerable period to return the system to standard process downward to that place.

\section{B. Power Loss}

A generating station is associated with the supply system at one place, and transmission line or transformer are disconnected from that point due to trips of protective relays so all of the power production is temporarily lost. So, all the loads are shifted to the other generating station and increase stress on the system so it may be root cause of cascade tripping and ultimately it leads to voltage collapse. This is exactly what happened in Québec 1989 [17]. 


\section{International Journal of Engineering Applied Sciences and Technology, 2020 \\ Vol. 5, Issue 8, ISSN No. 2455-2143, Pages 235-241 \\ Published Online December 2020 in IJEAST (http://www.ijeast.com)}

If the disconnection of generating station to transmission lines is due to damaged equipment then it takes longer time and large values can be lost in repairs cost.

Due to this sometimes apply balanced mitigation approach to reduce the burden on system or remove Transformers, at risk of everlasting destruction, at the time of GIC flow in power grid.

\section{Voltage Breakdown}

In electric transmission system high load can be a source of complications, one of them is voltage regulation.

Reactive power demand is increased drastically during magnetic storm which leads to increased tension in the power grid. At the time of increased demand and increased utilization of transmission capability, increased tension can lead to voltage drop like cold periods. Importunately consumption of the reactive power is associated with generation of harmonics, transformer heating and additional GIC connected threats who can lead the situation where transmission capacity and production are lost. So this thing can broad voltage drop in system. That was exactly occurred in Hydro-Québec 1989 incident.

Simulations done form Svenska Kraftnät during 2003[25] decided that in 2003 Swedish power system is capable to handle increased reactive power demand during the solar storm. They also conclude that the risk of voltage collapse could lead by following situations:

- High demand of power;

- High transmission voltage with multiple alternators, electricity cables, transformers and shunt capacitor banks out of order;

- Dangerous geoelectric field magnitude.

Inopportunely it's probable that the system won't be undamaged throughout large storms like a 100-year storm. To additionally examine the aftereffects of most extreme GIC ranges on the power grid system simulations must be executed. This type of model must take both element and grid results under considerations, so as to simulate the interrelationships aspects of GIC within the power grid.

Closedown of some selective portions of the grid is practicable during large geomagnetic storms. But it is not very smart mitigation strategy.

\section{Risk of supply network}

Transformers and electrical device extra components would have been lead-times within the very of 1 to 2 years in traditional market circumstances. It's affordable to imagine that geomagnetic storms sturdy adequate to wreck an electrical device up to that level it desires reparation or replacement may even have damaged different transformers, these raised demand for auxiliary components or backup unit may produce a universal deficiency of electrical device manufacturing ability.

\section{EFFECT OF GIC ON POWER SYSTEM APPARATUS}

\section{A. Power Transformer}

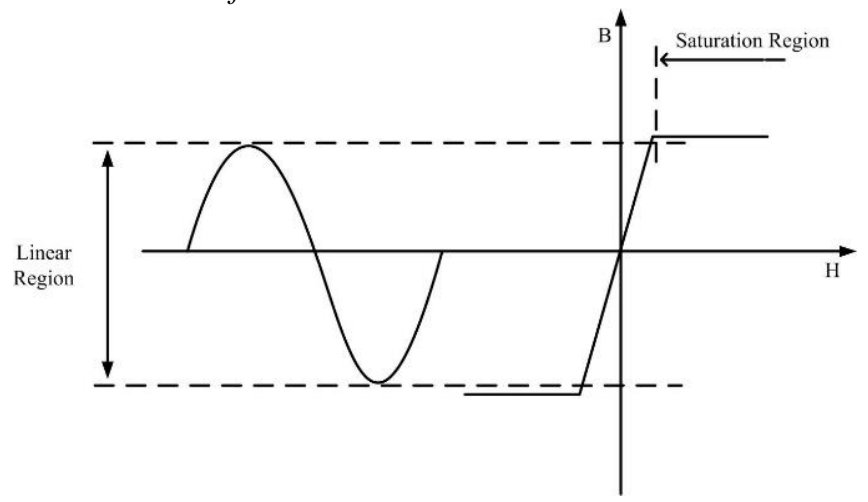

Figure 1: Transformer during Normal condition.

During standard process a transformer will function inside the linear region of core material saturation boundary (refer figure 1). For some cost saving reasons the quantity of core material in transformer is selected near to the desired operative boundary and even standard situations the transformer can use whole linear region till the knee point [26]. A transformer are design to use with $\mathrm{AC}$ power, direct current overlaid on the alternating current, that offsets the B-H curve vertically, so this can rapidly saturate the transformer core. Exactly this thing happen in the transformer when geomagnetically induced current enters from the transformer neutral [27]. The significances of this will discuss later in detail, but let see about saturation of different transformer cores and types.

In Hydro-Québec event most significant discovery is that dissimilar categories of transformers are affected totally dissimilar level. The responsiveness of GIC is depend on the transformer core design, it's a matter of arrival path of DC flux (refer figure 2). $3 \Phi$ transformers are less responsive than $1 \Phi$ transformers. Both 1 and $3 \Phi$ transformers are come in various dissimilar core schemes and they have dissimilarities in GIC susceptibility [28]. 3 legged and 5 legged three phase transformers are two most important types so we limit discussion around them.

Figure 2: Transformer content types. GIC damage varies between contextual species. The presence of a low backward path (downward arrows) increases the tendency for saturate during GIC caused DC bias. 

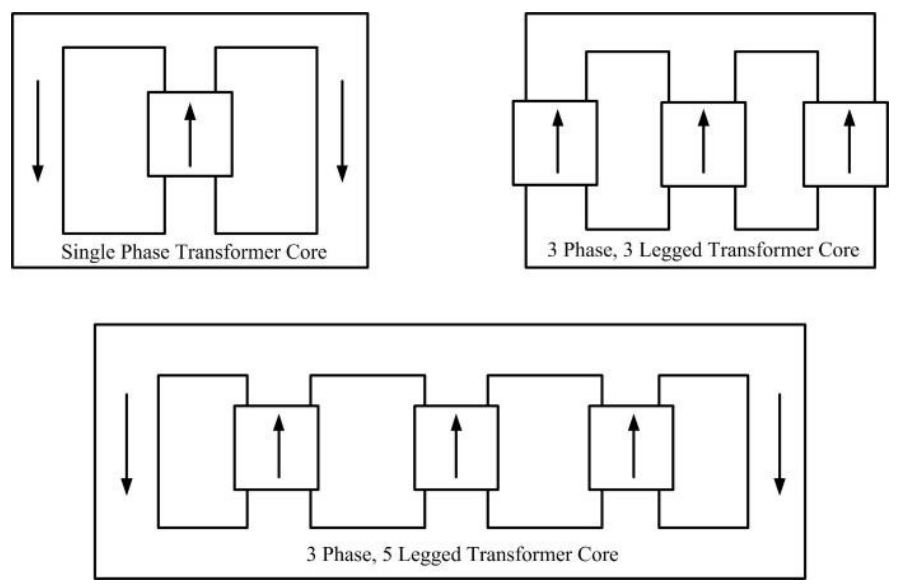

In Figure 2, the upward arrows symbolize the induction of magnetic flux through windings and the downward arrows symbolize the probable return paths for GIC made flux. As seen in figure $1 \Phi$ transformer and five legged $3 \Phi$ transformer have two downward arrows, giving warning that they are more suitable to saturate from DC bias. And this is the case where similar amount of GIC flow in the 3 legged transformer and 5 legged transformer but 3 legged transformer will not saturate as easily [29-32].

\section{Transformer Significances}

In transformer winding, when GIC start to flow through it then transformer core begin to saturate (refer figure $3)$. This saturation can create: (1) Generation of odd and even harmonics, (2) a large growth in reactive power demand and (3) Decrease efficiency of transformer and Increment of temperature [33]. The intensity of those reactions base on the power of the geomagnetic storm.

Exactly what happen when transformer core touches saturation? Permeability of the transformer core reduced drastically, that means impedance and inductions also will reduced. As impedance reduced, the magnetization current rises oppositely symmetrical to the drop as stated by Ohm law (refer figure 3 ). This will lead to a distortion of the alternating current.
2 Generation of Harmonics and Reactive Power Demand

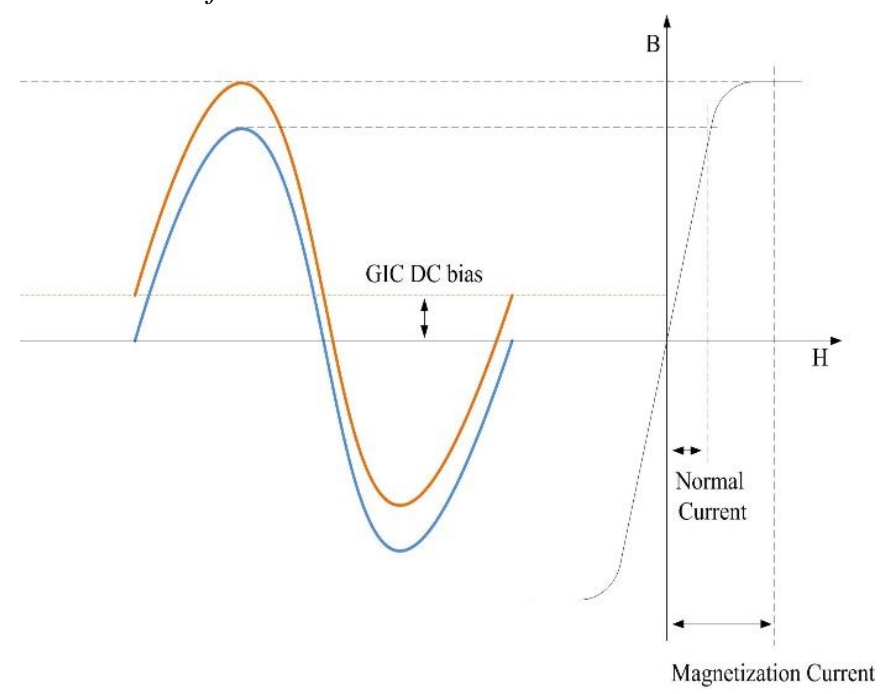

Figure 3: GIC in transformer. The blue lines indicate normal operation and the orange line indicates the state along with DC bias. As DC growth increases, forcing the transformer core into a half-cycle saturation, the magnetic field will increase significantly.

The increase in magnetizing current has significances to the power grid that is due to the distortion of the sinusoidal current. The brief note on above are as follows.

The magnetization current drastically increased when the transformer ranges to the saturation as discussed above (refer figure 3), the sinusoidal current is harshly distorted. Alternating Current power grids are planned for a pure sine wave kind of the current, thus distortion of sine wave can result in a range of issues. The measurement of the harmonic content in the current is due to the typical means of describing this feature of power quality.

Transformer turns into grand origin of odd and even harmonics is due to the flow of DC bias of GIC in the transformer neutral [34-36]. A number of complications in the power grid is because of the increment in harmonics content in the current, they are [32]:

- Malfunctioning of relays

- Production in Excess heat in capacitor banks

- Overburden on harmonic filters of High Voltage DC

- Raise in reactive power consumption

A considerable increment in reactive power demand is another result in enlarged magnetizing current. Thus, it leads to instability in power grid and hence threat of voltage drop.

\section{Heating of Transformer}

The other threat involving of the presence of GIC is heating of the transformer. The raised heating of a transformer through GIC encourage half-cycle core saturation because of two different processes. The one associate with heating of the 


\section{International Journal of Engineering Applied Sciences and Technology, 2020 Vol. 5, Issue 8, ISSN No. 2455-2143, Pages 235-241 \\ Published Online December 2020 in IJEAST (http://www.ijeast.com)}

winding and the other associate with leakage of magnetic flux [37].

According to the ohm's law, the current flows through a transformer winding. There are two parts of the transformer winding's impedance $(\mathrm{Z})$, first one is resistive and the second one is inductive part, in which the inductive part is supreme. When transformer are start to saturate, the inductance of winding reduces drastically and hence current rise rapidly, as mentioned above [26]. The rise in generation of heat in the windings is due to the growth in current flowing throughout the resistive portion of impedance. If permitted to carry on with the rise in heat generation in the winding will cause permanent harm to the windings and probably cause fire, leading to a harmful breakdown of the transformer.

\section{Heating because of Magnetic Flux Leak}

When transformer core starts to saturate, there will be no longer production of the induced magnetic flux in the primary winding along with a way of reduced magnetic reluctance. A structural component of transformer which is made up of ferromagnetic material, so the magnetic flux could try to find different return way of comparatively small reluctance. As these mechanisms, like pull roads, etc., they are not planned to reduce the eddy current generation from the leaking flux, so they begin to warm up. The high flux areas of the new return ways which get heating. This results into the harm of structural components of transformer. Overall increase in heat of the transformer and generation of gas in the tank of transformer oil. A small amount of temperature rise in transformer oil which decrease its capability to lower down the temperature in the transformer winding which leads to permanently destroy.

In 1989, storm in the Salem atomic power station in U.S. and "Halloween Storm" of 2003, in South Africa has been noticed permanent transformer damage. Also in 2003, transformer in Swedish Atomic power plant experienced in $13^{\circ} \mathrm{C}$ rise in the oil before taking any mitigation steps was taken to permit the transformer to calm down. Generation of gas in oil tank and burnt dye on transformer are different discovered GIC connected events $[14,21,22]$.

\section{Increase of Transformer Losses}

During experiments it observed that total transformer capability was reduced. The losses appear to rely linearly on Geomagnetically induced current, therefore in addition on the geomagnetically iatrogenic electric field and magnetic field [38].

\section{B. Malfunctioning of Protective Relays}

During geomagnetic storms malfunctioning of protective relay is very common failure type.

If power grid experiences a fault or operates in abnormal way then protective relay use to disconnect any component in the power grid. There are 2 principle ways in which a protecting relay will be untrustworthy, they will flop to work once required to or they will function once not required to. So dependability and security are the two reliability factors to take into considerations when setting these relays. The measure of the dependability is if any fault occur in power grid then relay have to function properly for all the types of faults that they are predictable to function for. The measure of safety is protective relay should not operate in correctively for any fault. These 2 factors are different and finding the correct balance between them will generally be tough [39].

The safety of protecting relays that's of the most interest during this GIC connected context. For example, throughout geomagnetic disturbance there is a probability of protecting relays misunderstanding the harmonic content within the alternating current and sense incorrect fault situations. While not entering in the one fact regarding the internal working of protecting relays, one will summarize that protecting relays are delicate to the harmonic content within the current and significantly to the $3^{\text {rd }}$ harmonics of the basic frequency [26]. As mentioned above at the time of GIC flow in transformer it can produce very high amount of harmonics. The protective relay may incorrectly sense a fault and give trip signal if the harmonic content is high enough.

The significance of wrong tripping of transmission conductors and instrumentation are mentioned in additional detail within the above chapter. When analyzing the results at system level because of the malfunctioning of relays, one should desire chance of many coincidental trips into examination meanwhile they are sometimes programmed to trip below comparable situations and a really high intensity storm will moderately be predictable to source these conditions on a huge area at a same time.

Blackout of Québec 1989 and power outage of Malmö in 2003 are the result of malfunctioning of protective relays [19, $20]$.

\section{SOME THINKABLE RISK TREATMENT STRATAGIES}

\section{A. Transformer Risk Treatment}

For stopping GIC through transformers there are several technical solutions thus it can decrease drastically the risk of one or bunch of transformers and in additionally decrease the system connected risks [30, 40].

- GIC blocking devices:

○ Use Neutral blocking devices in transformer;

- In transmission line use series compensators;

- Use capacitor at neutral of transformer as blocking device;

- Use resistor or reactor at neutral of transformer as blocking device;

- Use Polarization cells with solid state device;

- Live cancellation of GIC through auxiliary winding. 


\section{International Journal of Engineering Applied Sciences and Technology, 2020 \\ Vol. 5, Issue 8, ISSN No. 2455-2143, Pages 235-241 \\ Published Online December 2020 in IJEAST (http://www.ijeast.com)}

- Measure and get current time alerts of GIC from neutral of transformer and oil temperature of the transformer.

- Increase thermal convection use active cooling of transformer.

- To avoid permanent damage temporary disconnect the transformer from the grid.

\section{B. Relay Risk Treatment}

One of the foremost necessary experienced learned from each the Hydro-Québec occurrence in 1989 and also the power outage in Malmö throughout the Halloween storm in 2003 was the significance of the setting of accurate trip levels to keep away from malfunctioning because of GIC produced harmonics. An analysis of present relay settings and modification of procedures with reference to protecting relay including GIC in attention have tried to be one among the greatest cost effective method that to minimize power network wide GIC associated threat $[19,20]$.

\section{System Level Risk Treatment}

[24]:

For system level risk bellow mentioned steps can help

- Simulate whole power grid to find transformers at higher risk, to find suitable threshold levels for field \& GIC and calculate total reactive power requirement in the system.

- Take GIC under consideration once process new electrical device specification specially transformers and relays.

- Execution of mitigation strategies like a shutdown some parts of the whole system to decrease the consumption of the power and increase system stability to avoid voltage collapse during geomagnetic storm.

- Develop skills in the system operating personal to handle situation during the event of GIC.

- Make strategy for continuity of the electricity during GIC related events.

\section{CONCLUSION}

From this paper, it can be concluded that, in earlier days the effect of GIC was only seen in the polar region like Sweden, America, Canada, etc. But due to increasing transmission voltages the effects of GIC are also shown in lower-latitude areas like South Africa, New Zealand, China, etc. Due to the effects of GIC, many power system components are damaged and false tripping of the relay occurs. So that, the stability of power system is compromised.

The research on GIC is day by day increasing. Because, GIC easily enter in high voltage transmission line and damage the power system apparatus. The effect of GIC is mostly shown in transformer and relay. Due to half-cycle saturation of power transformer hotspot is created and damage or reduce the ability of the transformer. Also during half-cycle saturation, it draws very high amount of deformed transformer exciting current full of harmonics. The relay is a more sensitive device to the harmonics and harmonics produced by the presence of GIC which leads to false tripping of the relay.

For mitigation of GIC Passive device like reactor, resistor and capacitor can decrease the flow of current. It has very simple circuit and this devices can be installed easily. So that, this devices are used to mitigate GIC from the power system. But passive devices have its own limitations so now a day time to develop proper GIC mitigation device. Also mind GIC related risk during development of new transformer design.

\section{REFERENCE}

1. Wik, M.(2008), The sun, space weather and effects. : Lund University.

2. Arajärvi, E., R. Pirjola, and A.J.S.W. Viljanen(2011), Effects of neutral point reactors and series capacitors on geomagnetically induced currents in a high-voltage electric power transmission system. 9(11): p. 1-10.

3. Bernhardi, E., P. Cilliers, and C.J.S.A.J.o.S. Gaunt(2008), Improvement in the modelling of geomagnetically induced currents in southern Africa. . 104(7-8): p. 265-272.

4. Ma, Y.J., D.F. Wu, and X.S. Zhou.(2012) Research and assessments of geomagnetically induced currents. in Advanced Materials Research. . Trans Tech Publ.

5. Liu, C.M., et al.,(2009) Calculation of geomagnetically induced currents in mid-to lowlatitude power grids based on the plane wave method: A preliminary case study.. 7(4).

6. Ramírez-Niño, J., et al.,(2016) Core saturation effects of geomagnetic induced currents in power transformers. 14(2): p. 87-92.

7. Matandirotya, E., et al. (2016), Differential magnetometer method applied to measurement of geomagnetically induced currents in Southern African power networks. 2016. 14(3): p. 221-232.

8. Koskinen, H., et al.(2001), Space weather effects catalogue.

9. Pirjola, R., et al.(1998) Power and pipelines (ground systems). in Proceedings of a Workshop on Space Weather.

10. Barlow, W.H.J.P.T.o.t.R.S.o.L.(1849), VI. On the spontaneous electrical currents observed in the wires of the electric telegraph. 1849(139): p. 61-72.

11. N.R.C.J.h.w.n.e.c.(2008), Severe space weather events-Understanding societal and economic impacts: workshop report. 


\section{International Journal of Engineering Applied Sciences and Technology, 2020 \\ Vol. 5, Issue 8, ISSN No. 2455-2143, Pages 235-241 \\ Published Online December 2020 in IJEAST (http://www.ijeast.com)}

12. Edwall, H.-E. and D. Boteler.(2001) Studies of telluric currents on pipelines in Southern Sweden. in CORROSION 2001. 2001. NACE International.

13. Phillips, T.J.R.J.(2011), New solar cycle prediction. .

14. Baker, D., Balstad, R., Bodeau, J. M., Cameron, E., Fennell, J. F., Fisher, G. M., Forbes, K. F.,Kintner, P. L., Leffler, and L. L. G., W. S., Reagan, J. B., Small, A. A., Stansell, T.A., Strachan L.(2008), Severe space weather events: Understanding societal and economic impacts: A workshop report. 2008: National Academies Press.

15. McCracken, K., et al.(2001), Solar cosmic ray events for the period 1561-1994: 1. Identification in polar ice, 1561-1950. 2001. 106(A10): p. 21585-21598.

16. Pirjola, R.J. and D.H. Boteler.(2006) Geomagnetically induced currents in European high-voltage power systems. in 2006 Canadian Conference on Electrical and Computer Engineering. 2006. IEEE.

17. Viljanen, A.J.S.W.(2011), European project to improve models of geomagnetically induced currents. 2011. 9(7).

18. Beggan, C.D., et al.(2013), Prediction of extreme geomagnetically induced currents in the UK highvoltage network. 2013. 11(7): p. 407-419.

19. Hydro-Québec (n.d.). March 1989 Blackout. Retrieved June 27, from Hydro-Québec: and http://www.hydroquebec.com/learning/notions-debase/tempete-mars-1989.html, 2011.

20. Malmgren, J., Störningsutredning. (2003), NA-0310044, Sege, Jordmagnetisk störning 2003-10-30 kl 21.07 (in Swedish).

21. Marusek, J.A.(2007), Solar storm threat analysis. 2007: J. Marusek.

22. Gaunt, C. and G. Coetzee.(2007) Transformer failures in regions incorrectly considered to have low GICrisk. in 2007 IEEE Lausanne Power Tech. 2007. IEEE.

23. Trivedi, N.B., et al.(2007), Geomagnetically induced currents in an electric power transmission system at low latitudes in Brazil: A case study. 2007. 5(4): p. 110.

24. Thorberg, R.J.D.o.I.E.E. and L.(2012) Automation Faculty of Engineering, Lund University, Risk analysis of geomagnetically induced currents in power systems. 2012.

25. Kielén, B.J.S., Sweden: Elforsk AB,(2004) Solstormar, transienta geomagnetiska störningar, Elforsk report 03: 33. 2004.

26. Molinski,(2002) T.S.J.J.o.a. and s.-t. physics, Why utilities respect geomagnetically induced currents. 2002. 64(16): p. 1765-1778.

27. Liu, J., et al.(2016), The response of local power grid at low-latitude to geomagnetic storm: An application of the Hilbert Huang transform. 2016. 14(4): p. 300312.
28. Bozoki, B.(1996), et al., The effects of GIC on protective relaying. 1996. 11(2): p. 725-739.

29. Rejminger,(1996) A.J.E.E., Transformatorer. 1996: p. 1-78.

30. Andréasson, K.(2006), Transformatorers dimensionering med avseende på geomagnetiskt inducerad ström i kraftsystemet. 2006.

31. Lindahl, S.(2003), Effect of geomagnetically induced currents on protection systems. 2003: Elforsk.

32. Fuchs, E. and M.A. Masoum,(2011) Power quality in power systems and electrical machines. 2011: Academic press.

33. Lu, S. and Y.J.I.T.o.P.D. Liu,(1993) FEM analysis of DC saturation to assess transformer susceptibility to geomagnetically induced currents. 1993. 8(3): p. 1367-1376.

34. Lu, S., Y. Liu, and J.J.I.T.o.p.D. De La Ree,(1993) Harmonics generated from a DC biased transformer. 1993. 8(2): p. 725-731.

35. Ma, X.L., et al.(2010) Simulation study on converter transformer saturation characteristics due to GIC. in CICED 2010 Proceedings. 2010. IEEE.

36. Kappenman, J., et al.(1981), Current transformer and relay performance in the presence of geomagneticallyinduced currents. 1981(3): p. 1078-1088.

37. Kappenman, J.G.J.I.P.E.R.(1996), Geomagnetic storms and their impact on power systems. 1996. 16(5).

38. Lahtinen, M. and J.J.I.T.o.P.D. Elovaara,(2002) GIC occurrences and GIC test for $400 \mathrm{kV}$ system transformer. 2002. 17(2): p. 555-561.

39. Horowitz, S.(2003), Power System Relaying (Lines and Cables for Power Transmission Series, 7). 2003, Baldock, UK: Research studies press LTD.

40. Kappenman, J.J.F.(2010), Metatech Corporation, Low-frequency protection concepts for the electric power grid: geomagnetically induced current (GIC) and E3 HEMP mitigation. 2010. 